\title{
A Study of Effectiveness of Learning Experience through YouTube: Case Study: Adobe Photoshop CC
}

\author{
Muhammad Firdaus Muhammad Husni Tamrin*, Nur Aniza Mohd Lazim, Andrialis \\ Abdul Rahman, Siti Norfatulhana Ishak and Ruhil Nadiah Abu Bakar \\ Faculty Art \& Design, Universiti Teknologi MARA (UiTM), Malaysia
}

\begin{abstract}
This research is regarding effective learning experience from components of perception, usefulness and satisfaction. A case study discusses video tutorial Photoshop CC (Creative Cloud) through YouTube. Adobe Photoshop CC is software that becoming prevalent among university students especially in the field of art and photography. It is an amazing tool that allows people to bring out their creativity in editing photos, creating websites, advertisement, newsletters and many more. In mastering how to use the software, tutorial videos can be one of the best methods for learning purposes. The purpose of this paper is to analyse student's experience of existing tutorial Photoshop videos on YouTube. The methodology used in this paper is a mixed method. Total samples of 60 questionnaires were collected using an online channel, involving students from level Diploma, Bachelor's degree and Master's Degree. Results showed most of the respondents learning Photoshop tutorial through YouTube as a learning platform. Majority of the respondents agreed that videos tutorial Photoshop mostly used in English language and sometimes it might difficult to understand. Additionally, most of them also agreed that they need to spend time more to learn the video tutorial because of duration is too long. Therefore, it has been suggested that videos should be done in a short duration which is less than 5 minutes and provide other languages including Malay as well.
\end{abstract}

Keywords: Learning experience, Effective learning, Online learning, Online distance learning, YouTube

\section{Introduction}

Therefore, this study used social media as an essential tool in tutoring Photoshop for first time user through YouTube online channel since YouTube offers a huge range of instructional videos with free access (BuzzettoMore, 2014). Interestingly, numerous video clip has been uploaded every minute to make it a feasible choice for a student to obtain useful information for learning purpose. Additionally, YouTube has a high ability to develop student's learning skills (Ebied, 2016). There are many YouTube content represents "tutoring Photoshop" which can lead a beginner deeper understanding of learning subject. The word "tutorial" is commonly interpreted as a tool for providing easy guidelines to be followed and learning knowledge by imitating the procedures as presented.

Adobe Photoshop software had existed the first version since 2003 but it is a challenging software editing to study. In the part of that, Photoshop book has been published in the market about a decade in Malaysia. According to the Maziriri (2020) stated that more than $80 \%$ of all participants have used the YouTube tutorial for educational purpose. Kemp (2020), reported that over 25 million (78\%) of Malaysian who are active on social media. Apart from that, the time spent in teaching and learning session is limited. It will be affected by a large number of students, teachers are not able to pay full attention. As a result, some students are unable to focus will be left behind (Batumalai, 2019). Moreover, the Photoshop tutorial through YouTube is usually used 
in the English language. Therefore, people who like to hear and read the needed a plain language to understand more about the information (Franko 2016).

There are three purposes to study effective learning experience through YouTube. The first was to identify the features used for tutoring Photoshop on YouTube. The second purpose of this study was to analyse student's perception, usefulness and satisfaction of existing Photoshop tutorial video on YouTube. The third is to develop a Photoshop tutorial video that required among UiTM students.

\section{Methodology}

This research is using both methods for further deeper understanding. The qualitative approach is more objective and enables the representative sample to be collected and used the visual analysis to collect data from videos of Photoshop tutorial on YouTube channel. The qualitative for this study is to identify the features used tutoring Photoshop videos on YouTube.

Meanwhile, in quantitative approach, the online survey outcome has been conducted among $n=60$ students in the department of Art and Design at Universiti Teknologi MARA (UiTM) Shah Alam, Puncak Alam and Seri Iskandar. It has been conducted by using a proper online channel. The questionnaire was divided into pre-test and post-test. The pre-test is included a section of demographic profile and the section of student's perception. However, the post-test is divided into 4 sections that involved the demographic profile, student's perception, perceived usefulness and perceived satisfaction. The result from student's perception will be done with the comparison between pre-test and post-test data. However the division of answers based on a five-point Likert scale. In an example, point 1 strongly disagrees, point 2 disagrees, point 3 is neutral, point 4 agrees and point 5 is strongly agree. The data were analysed through the statistical software IBM SPSS v23.0.

\section{Results and Discussion}

\section{The features used for tutoring Photoshop videos in YouTube.}

From 12 difference types of tutorial Photoshop video, it can be concluded that there are six important features and can be categories the language, screencast, duration, highlight mouse point, keyboard shortcut and voice over.

\section{Student's perception, usefulness and satisfaction of existing Photoshop tutorial video in YouTube.}

\section{Demographic data}

Overall, total respondents in this research are $\mathrm{n}=60$ among students of UiTM Shah Alam, Puncak Alam and Seri Iskandar. The percentage of respondents in gender consists of the male which involves $40 \%$ (24) followed by female comprised of $60 \%$ (36). This result showed that female respondents are more numerous than male respondents. The age of respondents consists of 18 to 23 years old which is involve $65 \%$ (39), 24 to 29 years old $31.7 \%$ (19) and the same number of respondents in age 30 to 35 years old and 36 years old and above which is $1.7 \%$ (1). The level of education indicates the respondents among Diploma which is $25 \%$ (15), Bachelor Degree is $53.3 \%$ (32) and Master Degree is $21.7 \%$ (13). Meanwhile in the year of study were divided into three categories among the respondents. Majority of respondents are Year 1 which is comprised of $50 \%$ (30). Meanwhile, 31.7\% (19) of the respondents are Year 3 and only 18.3\% (11) are Year 2. Besides, the result shows of the highest respondents who are learning Photoshop through YouTube which is 75\% (45). Meanwhile, 25\% (15) of the respondents are learning from Photoshop book. 
Table 1: The time spending of learning Photoshop in classroom is enough.

\begin{tabular}{|ll|l|l|l|l|}
\hline & & & & Cumulative \\
& & Frequency & Percent & Valid Percent & Percent \\
\hline Valid & Yes & 10 & 16.7 & 16.7 & 16.7 \\
& No & 26 & 43.3 & 43.3 & 60.0 \\
& Maybe & 24 & 40.0 & 40.0 & 100.0 \\
& Total & 60 & 100.0 & 100.0 & \\
\hline
\end{tabular}

Table 1 shows that majority of respondents have not enough time to learn Photoshop from the classroom that is consist of $43.3 \%$ (26). Meanwhile, $40 \%$ (26) are maybe and $16.7 \%$ (10) is enough time to learn.

Table 2 below shows the result of pre-test and post-test. The pre-test questionnaire is about student's perception of learning Photoshop from YouTube video titled "How to Cut-out \& Retouch a Product in Photoshop CC 2017 | Tea Tree Product Photography" by Asm Arif channel. Whereas the post-test is about student's perception of learning Photoshop from YouTube video titled "Cara Mudah Mengedit Produk Komersial Dengan Menggunakan Selection Tool" by Firdaus Husni channel.

Table 2: The student's perceptions of learning Photoshop from YouTube video.

\begin{tabular}{lllll}
\hline Likert - type Items & \multicolumn{3}{l}{ Pre-test } & \multicolumn{3}{l}{ Post-test } \\
\cline { 2 - 6 } & Mean & SD & Mean & SD \\
\hline 1. Learn through this video is effective and efficient. & 4.22 & 0.761 & 4.43 & 0.621 \\
2. Many ways and techniques I can learn. & 4.28 & 0.691 & 4.38 & 0.666 \\
3. This video is easy to understand and pronunciation is good. & 4.13 & 0.812 & 4.57 & 0.593 \\
4. This video can improve my skills. & 4.27 & 0.778 & 4.37 & 0.663 \\
5. This video enhance my learning and understanding & & & & \\
of content. & 4.20 & 0.755 & 4.45 & 0.565 \\
6. My learning achievement is increase. & 4.05 & 0.746 & 4.47 & 0.623 \\
7. This video can enhance my learning process. & 4.17 & 0.763 & 4.42 & 0.646 \\
8. The explanation from this video is too long & 3.98 & 0.833 & 2.25 & 1.174 \\
9. I prefer simple and straightforward explanation. & 4.27 & 0.841 & 4.02 & 0.892 \\
10. I need to spend more time to learn from this video. & 4.02 & 0.792 & 2.60 & 1.392 \\
11. Video duration should be less than 5 minutes. & 3.92 & 1.062 & 3.77 & 1.064 \\
12. I found tutorial Photoshop in YouTube mostly used & & & & \\
in English language. & 4.38 & 0.739 & 4.23 & 0.909 \\
13. The English language sometimes difficult to understand. & 3.67 & 1.115 & 4.05 & 1.016 \\
14. Photoshop tutorial should be done in Malay language. & 3.87 & 1.127 & 4.28 & 0.846 \\
15. Screencast should provide in tutorial video. & 3.92 & 1.013 & 4.10 & 0.730 \\
16. I prefer keyboard shortcut in tutorial video. & 3.72 & 1.106 & 4.20 & 0.798 \\
17. Highlight mouse point is necessary in tutorial video. & 4.28 & 0.715 & 4.42 & 0.696 \\
18. Listening through voice over is better than music & & & & \\
background. & 4.23 & 0.851 & 4.50 & 0.567 \\
\hline
\end{tabular}

Table 2 shows the statement number 11 which is "video duration should be less than 5 minutes" has found that the mean score for pre-test is 3.92 and decrease to 3.77 (post-test). The result shows the majority of respondent 
agree the video should be less than 5 minutes. According to Guo (2014), stated that "video under 3 minutes yielded the highest engagement for user".

Table 3: The usefulness of learning Photoshop from YouTube video by Firdaus Husni channel.

\begin{tabular}{lll}
\hline Likert - type Items & Mean & SD \\
\hline 1. Malay language make it easier to editing in Photoshop & 4.48 & 0.700 \\
2. Screencast is useful. & 4.27 & 0.710 \\
3. Short duration is able to grab attention. & 4.28 & 0.691 \\
4. Highlight of mouse point is useful. & 4.42 & 0.591 \\
5. Keyboard shortcut is important. & 4.53 & 0.623 \\
6. Voice over is clear and understandable. & 4.47 & 0.566 \\
7. Overall video is useful and attract until the end of video & 4.37 & 0.610 \\
8. It motivate me to learn more. & 4.40 & 0.558 \\
\hline
\end{tabular}

Based on table 2, the highest mean score of the usefulness is keyboard shortcut which is 4.53 . Furthermore, the Malay language makes it easier to editing is recorded as 4.48 meanwhile the voice over is clear and understandable stated as 4.47. While the lowest mean score of usefulness is screencast which is 4.27. The respondents tend to learn Photoshop more on keyboard shortcut, Malay language, and voice over is understandable. According to Buchner (2018), stated that "music, background noise and extra features that can divert attention from the instructional content are elements that should be avoided".

Table 4: The satisfaction of learning Photoshop from YouTube video by Firdaus Husni channel.

\begin{tabular}{lll}
\hline Likert - type Items & Mean & SD \\
\hline 1. Satisfied with Malay language. & 4.52 & 0.596 \\
2. Video duration are expected. & 4.40 & 0.643 \\
3. Screencast video quality is wonderful. & 4.45 & 0.594 \\
4. Satisfied with keyboard shortcut. & 4.55 & 0.565 \\
5. Felt fun to learn. & 4.38 & 0.585 \\
6. Satisfied with highlight mouse point & 4.48 & 0.537 \\
7. Satisfied with voice over & 4.43 & 0.593 \\
8. Recommended to friend & 4.50 & 0.537 \\
\hline
\end{tabular}

Based on table 3, the highest mean score of satisfaction is a keyboard shortcut which is 4.55 . Furthermore, the respondents are satisfied with the Malay language recorded as 4.52 meanwhile they are satisfied with the highlight mouse point stated as 4.48 . While the lowest mean score of satisfaction is felt fun to learn which is 4.38. The respondents satisfied more on keyboard shortcut, Malay language, and highlight mouse point.

\section{Conclusion}

The study of effective learning experience through YouTube has found the result indicate that respondents satisfied with the new video tutorial Photoshop in Malay language and they felt the video is useful for them. Majority of the respondents agreed that videos tutorial Photoshop mostly used in English language and sometimes it might difficult to understand. Additionally, most of them also agreed that they need to spend time more to learn the video tutorial because of duration is too long. Therefore, it has been suggested that videos should be done in a short duration which is less than 5 minutes and provide other languages including Malay as well. 


\section{References}

Batumalai, V. \& Kamarudin, N. (2019). 'Blended Learning' as an Effective Teaching and Learning strategy in the Classroom'. In proceeding of graduate research in education seminar 2019. Faculty of Educational Studies, Universiti Putra Malaysia.

Buchner, Josef. (2018). How to create Educational Videos: From watching passively to learning actively.

Buzzetto-More, N. A. (2014). An examination of undergraduate student's perceptions and predilections of the use of YouTube in the teaching and learning process. Interdisciplinary Journal of E-Learning and Learning Objects, 10(1), 17-32.

Ebied, M.A., Kahouf, S.A., \& Rahman, S. (2016). Effectiveness of Using Youtube in Enhance the Learning of Computer in Education Skills in Najran University. International Interdisciplinary Journal of Education, 5, 619625.

Franko, R. (2016). Video tutorial making as a business: video tutorials through the lens of photography.

Guo, P.J., Kim, J., \& Rubin, R. (2014). How video production affects student engagement: An empirical study of MOOC videos. Paper presented at the the first ACM conference on Learning@ (L@S'14), Atlanta, GA.

Maziriri, E. \& Gapa, P. \& Chuchu, T. (2020). Student Perceptions Towards the use of YouTube as an Educational Tool for Learning and Tutorials. International Journal of Instruction. 13. 119138.10.29333/iji.2020.1329a.

Kemp, S. (2020). Digital 2020: Global Digital Overview - Data Reportal - Global Digital Insights. Retrieved from https://datareportal.com/reports/digital-2020-global-digital-overview. 